\title{
3D Porous Calcium-Alginate Scaffolds Cell Culture System Improved Human Osteoblast Cell Clusters for Cell Therapy
}

\author{
Ching-Yun Chen ${ }^{1}$, Cherng-Jyh Ke ${ }^{2,3}$, Ko-Chung Yen ${ }^{1}$, Hui-Chen Hsieh ${ }^{1}$, Jui-Sheng Sun ${ }^{3,4,5,6 * \varpi}$, Feng-Huei \\ $\operatorname{Lin}^{1,7^{*} \bowtie}$ \\ 1. Institute of Biomedical Engineering, College of Medicine and College of Engineering, National Taiwan University, Taipei, Taiwan (R.O.C.). \\ 2. Biomaterials Translational Research Center, China Medical University Hospital, Taichung, Taiwan (R.O.C.). \\ 3. Department of Biomedical Electronics Translational Research Center and Biomimetic Systems Research Center, National Chiao Tung University, \\ Hsinchu, Taiwan (R.O.C.). \\ 4. Department of Orthopedics, College of Medicine, National Taiwan University, Taipei, Taiwan (R.O.C.). \\ 5. Department of Orthopedic Surgery, National Taiwan University Hospital, Taipei, Taiwan (R.O.C.). \\ 6. Department of Orthopedic Surgery, National Taiwan University Hospital, Hsin-Chu Branch, Hsinchu, Taiwan (R.O.C.). \\ 7. Institute of Biomedical Engineering and Nanomedicine (I-BEN), National Health Research Institutes, Miaoli, Taiwan (R.O.C.) \\ * These authors contributed equally to this work.
}

$\triangle$ Corresponding authors: Feng-Huei Lin, Life Distinguished Professor, Institute of Biomedical Engineering, National Taiwan University, Taipei, Taiwan, R.O.C. Tel: +886-2-23123456 ext. 88766 or 81456; Fax: +886-2-23940049; E-mail: double@ntu.edu.tw or Jui-Sheng Sun drjssun@gmail.com

C 2015 Ivyspring International Publisher. Reproduction is permitted for personal, noncommercial use, provided that the article is in whole, unmodified, and properly cited. See http://ivyspring.com/terms for terms and conditions.

Received: 2014.12.17; Accepted: 2015.02.04; Published: 2015.03.01

\begin{abstract}
Age-related orthopedic disorders and bone defects have become a critical public health issue, and cell-based therapy is potentially a novel solution for issues surrounding bone tissue engineering and regenerative medicine. Long-term cultures of primary bone cells exhibit phenotypic and functional degeneration; therefore, culturing cells or tissues suitable for clinical use remain a challenge. A platform consisting of human osteoblasts (hOBs), calcium-alginate (Ca-Alginate) scaffolds, and a self-made bioreactor system was established for autologous transplantation of human osteoblast cell clusters. The Ca-Alginate scaffold facilitated the growth and differentiation of human bone cell clusters, and the functionally-closed process bioreactor system supplied the soluble nutrients and osteogenic signals required to maintain the cell viability. This system preserved the proliferative ability of cells and cell viability and up-regulated bone-related gene expression and biological apatite crystals formation. The bone-like tissue generated could be extracted by removal of calcium ions via ethylenediaminetetraacetic acid (EDTA) chelation, and exhibited a size suitable for injection. The described strategy could be used in therapeutic application and opens new avenues for surgical interventions to correct skeletal defects.
\end{abstract}

Key words: Three-dimensional culture, Preformed scaffolds, Bone-like tissues, Perfusion, Autografts

\section{Introduction}

The loss or failure of an organ or tissue is a very severe human health problem. Tissue engineering (TE) is an interdisciplinary field that combines the principles of engineering and biosciences with the goal of achieving human tissue regeneration or reconstruction [1-3]. Tissue engineering aims at developing engineered tissues or substitutes created in vitro that restore, maintain or improve tissue function [4-6]. 
As worldwide life expectancy increases annually, age-related skeletal diseases are becoming a serious health concerns in almost every population [7, 8]. Age-related osteoporotic bone loss is a universal phenomenon and cause fragility fractures. Moreover, regeneration of bone defects remains one of the most significant challenges faced in reconstructive surgery [9]. Considering that spontaneous bone regeneration is limited to relatively small defects, bone graft material is often required for the treatment of large bone defects caused by traumatic injury, osteomyelitis, tumor removal or implant loosening [10, 11]. However, owing to limitations and risks associated with autologous as well as allogenic bone grafting procedures, alternative strategies are required.

Recent ex vivo TE strategies for de novo generation of bone tissue include the combined use of autologous bone-forming cells and three-dimensional porous scaffold materials serving as structural support for the cells. Human cells are extremely sensitive to culture environments and signal stimulation, and the three dimensional (3D) cultivation of osteoprogenitor cells presents several challenges, such as insufficient nutrients and oxygen transport to and removal of waste products from the cells residing in the scaffold. Bioreactor systems have become key components of bone TE strategies by providing physical stimulation of tissue-engineered constructs and by allowing mass transport to and from the cells. However, designing an ideal bioreactor system is challenging. A bioreactor system is defined as a close culture environment that allows medium flow perfusion and containing scaffolds designed to improve cell proliferation and function [12].

Because the differentiation of cells is greatly influenced by the niche that harbors undifferentiated precursors and by both intrinsic and extrinsic signals, a two dimensional (2D) culture approach presents critical limitations resulting in low differentiation efficiency [13]. Therefore, improving the performance of transplanted cells requires a better understanding of the cellular mechanisms guiding cell behavior in both native and engineered 3D microenvironments. However, most techniques for investigating mechanisms controlling cell behavior in vitro have been developed using 2D cell culture systems and are of limited use in 3D environments, such as engineered tissue constructs. The biasing of cell function that occurs with traditional methods of 2D culture, leads to unpredictable in vivo results that hamper translation into the clinic. Developing novel methods to investigate cell function in engineered 3D microenvironments promises to preserve the control mechanisms present in the native cell niche and to create functional engineered tissues in a more predictable, reliable and safe manner
[14]. Dynamic 3D bioreactors mimicking the native microenvironment of bone tissue, such as spinner flasks, rotating wall vessel constructs, perfusion bioreactors and systems based on mechanical or electromagnetic stimulation of cell/scaffold composites, have been developed. These solutions to 3D culture differ considerably with respect to ease of use, cost-effectiveness and degree of osteogenic stimulation, as well as with respect to options for cell monitoring and manipulation [8].

In regenerative medicine, a synthetic extracellular matrix ECM is crucial for supporting stem cells during the differentiation process and for integration into surrounding tissues. To overcome the limitations of 2D culture systems, 3D culture platforms such as highly porous, biomimetic scaffolds were used to increase cell differentiation efficiency. Alginate is a family of natural polysaccharides composed of $\beta$-D-mannuronate and $\alpha$-L-glucuronate that has been widely used in tissue engineering [15-20]. Alginate at room temperature can form non-covalent crosslinks through interaction with bivalent metal ions, such as calcium ions [17, 21]. Hydrophilic alginate hydrogels have raised special interest as a mean to provide a temporary support for a variety of cell types [22], including osteoblasts [23], chondrocytes [24], fibroblasts [25] and embryonic stem cells [18, 26]. Moreover, alginate scaffolds with high porosity and interconnectivity can be created via the freeze-drying technique [27]. Because of the spongy structure of alginate scaffolds, cells can be transferred into the scaffold by capillary action and quenched by the hydrogel-like structure of the scaffold.

In this study, we developed a functionally closed process bioreactor with a $3 \mathrm{D}$ porous Ca-Alginate scaffold cell culture system to mimic the in vivo environment in order to form bone-like tissue. Perfusion-based bioreactors are frequently composed of chambers or cartridges harboring the cell/scaffold constructs and the operating parameters of these instruments include the temperature, gas exchange, nutrient transport, signal induction and mechanical force [8]. In contrast to other commercial bioreactor systems, the bioreactor system developed in this study could be compatible with variable scaffolds, support the growth and differentiation of various cell types and provide a high-throughput cell culture system. Furthermore, all components of the apparatus (bottles and tubes) are disposable, and the price would be affordable for patients in need of cell therapy. Most importantly, the bioreactor device would be operated under close-loop conditions to avoid contamination. In summary, the functionally closed process bioreactor system developed by our laboratory is more affordable than other systems currently 
on the market and would be a valuable alternative for physicians and patients in need of such devices.

\section{Materials and Methods}

\section{Materials and reagent}

Pharmaceutical-grade sodium alginate (Keltone ${ }^{\circledR}$ LV) was a gift from FMC BioPolymer Corporation (Philadelphia, PA, USA). Calcium chloride, dexamethasone, beta-glycerophosphate, 2-phosphoL-ascorbic acid and citric acid were procured from Sigma-Aldrich (St. Louis, MO, USA).

Cell culture medium, antibiotics, fetal bovine serum, trypsin-EDTA and TRIzol ${ }^{\circledR}$ were obtained from Life Technologies, Inc. (Carlsbad, CA, USA). Cell culture dishes and plates were obtained from Corning Life Sciences, Inc. (Acton, MA, USA). OmicsGreen qPCR Master Mix was sourced from Omics Biotechnology Co. (Taipei, Taiwan). Optical reaction plate, and optical adhesive covers for real-time PCR were procured from Life Technologies, Inc. (Carlsbad, CA, USA).

\section{Ca-Alginate scaffold fabrication and prepara- tion}

The Ca-Alginate scaffolds were prepared by a freeze-drying technique as described previously [27]. Briefly, $1.5 \mathrm{wt} \%$ pharmaceutical-grade sodium alginate (Keltone ${ }^{\circledR}$ LV, FMC BioPolymer) powder was dissolved in deionized water, and injected into 48-well culture plate with the volume of $1 \mathrm{~mL} /$ well. The polymer solution was frozen at $-20^{\circ} \mathrm{C}$ overnight and then fabricated into porous structure by freeze-drying technique. The spongy scaffolds were cross-linked in $2 \%$ calcium chloride solution at room temperature for $1 \mathrm{~h}$, then sterilized with $75 \%$ alcohol, dehydrated in a gradient series of ethanol and stored at room temperature until use.

\section{hOBs isolation and expansion}

hOBs were collected from the spongy or cancellous bone chips of resected bone after total hip/knee joint replacement surgery (IRB No. 201012057RB). The bone chips were cut into approximately $1 \mathrm{~mm} \times 1 \mathrm{~mm}$ bone fragments washed with phosphate buffered saline (PBS). Fragments were digested by alpha-modified minimum essential medium (a-MEM) containing $0.2 \%$ type I collagenase for $24 \mathrm{~h}$ at $37^{\circ} \mathrm{C}$. After collagenase digestion, the washed bone fragments were cultured in standard culture medium consisting of alpha-modified minimum essential medium (a-MEM) containing 20\% fetal bovine serum (FBS) with $1 \%$ antibiotics, $0.1 \mu \mathrm{M}$ dexamethasone (Dex), $10 \mathrm{mM}$ beta-glycerophosphate $(\beta-\mathrm{GP})$, and 0.2 mM 2-phospho-L-ascorbic acid (Asc 2-P). The fragments were incubated at $37^{\circ} \mathrm{C}$ in a humidified incu- bator with $5 \% \mathrm{CO}_{2}$ and the culture medium was changed every 2 days. After approximately 4-6 weeks in culture, hOBs were harvested for further expansion. Cells used in the study were from passage three to four.

\section{Development of functionally-closed process bioreactor system}

The functionally-closed process bioreactor system used in this study was described previously [28]. Briefly, the bioreactor system could be divided into two parts: cell culture tank and culture medium tank. The cell culture tank of the bioreactor system was composed of a $50 \mathrm{~mL}$ sterile centrifuge tube and a glass casing pipe for mass transferring. The culture medium tank of the bioreactor system is a $500 \mathrm{~mL}$ glass bottle with a plastic cap, which comprised 4 stainless ports for medium and gas perfusion. All consumables of the bioreactor system were sterilizable via autoclaving or EO sterilization. The whole system was installed inside an incubator with humidified air $\left(37^{\circ} \mathrm{C}, 5 \% \mathrm{CO}_{2}\right)$. The flow rate was $1 \mathrm{~mL} / \mathrm{min}$ controlling via a peristaltic pump (LongerPump), which provided continuous medium replenishment.

\section{Characterization of Ca-Alginate scaffolds}

The calcium ion concentration was measured by inductively coupled plasma optical emission spectrometry (ICP-OES, Agilent 725, Agilent Technologies). And the porosity of Ca-Alginate scaffolds was determined by mercury intrusion porosimetry (MIP, AutoPore IV 9520, Micyromeritics Instrument). The principle of MIP analysis depends on the intrusion of mercury into porous materials under stringently controlled pressures, and AutoPore IV 9520 provides the dynamic range of pore size distribution between 0.003 to 360 micrometers. Simultaneously, the BET surface area and the Langmuir surface area of Ca-Alginate scaffolds were evaluated by nitrogen adsorption experiments (Micromeritics ASAP 2010 analyzer, Micromeritics Instrument).

\section{Cell seeding method}

The Ca-Alginate scaffolds were sterilized with $75 \%$ ethanol. The hOBs were suspended in medium and then seeded into scaffolds at a density of $5 \times 10^{5}$ viable cells/scaffold. The scaffolds with hOBs were placed in a 24-well culture plate for $24 \mathrm{~h}$ for cell adhesion, and then cultured in functionally-closed process bioreactor system for 1-2 weeks. The medium was circulated with an initial pump setting of 1 $\mathrm{mL} / \mathrm{min}$ via a peristaltic pump.

\section{Cell proliferative quantification}

Cell proliferative quantification was assessed through Alamar Blue (Life Technologies) reduction 
ability of the hOBs in Ca-Alginate scaffold in accordance with the manufacturer's protocol. In brief, working solution was comprised of $10 x$ dilution from stock Alamar Blue reagent with serum-free a-MEM. Each Ca-Alginate scaffold was reacted with $2 \mathrm{ml}$ working solution in $15 \mathrm{ml}$ sterile centrifuge tube in an incubator for $1 \mathrm{~h}$ and was kept in the dark. The relative fluorescence response of Alamar Blue reduction was measured at $530 \mathrm{~nm}$ excitation and $590 \mathrm{~nm}$ emission using a fluorescent microplate reader (SpectraMax M5, Molecular Devices).

\section{Live/Dead staining}

After being cultured for 1, 7, and 14 days, bone-like tissues in Ca-Alginate scaffolds were stained with $4 \mu \mathrm{M}$ calcein AM (Life Technologies) and $4 \mu \mathrm{M}$ of propidium iodide (PI, Life Technologies) for $30 \mathrm{~min}$. Live cells were showed green fluorescence by calcein AM (ex/em $\sim 495 \mathrm{~nm} / \sim 515 \mathrm{~nm}$ ), and dead cells stained red by Aqua-fluorescent reactive dye PI (ex/em $\sim 540 \mathrm{~nm} / \sim 615 \mathrm{~nm})$. Cell survival was observed by a confocal microscope (LSM 780, Zeiss), and 3D cell images were reconstructed.

\section{SEM and EDX analysis}

The morphology of bone-like tissues wrapping inside Ca-Alginate scaffolds was observed by field emission gun scanning electron microscopy (FEG-SEM, JSM-6330F, JEOL). Briefly, cells in Ca-Alginate scaffolds were fixed with $4 \%$ para-formaldehyde (PFA) for $2 \mathrm{~h}$ and $2 \%$ osmium tetroxide $\left(\mathrm{OsO}_{4}\right)$ solution for $1 \mathrm{~h}$. All the samples were dehydrated in a graded series of ethanol, dried by critical-point drying (CPD) method, and sputter-coated with gold to a thickness film before observation.

\section{Cell cluster size distribution}

After 1-2 weeks culture in bioreactor system, bone-like tissues were released from Ca-Alginate scaffolds by dissolving in $50 \mathrm{mM}$ EDTA solution at $37^{\circ} \mathrm{C}$ for $5 \mathrm{~min}$. The bone-like tissues were rinsed with PBS and fixed with $4 \%$ para-formaldehyde for $15 \mathrm{~min}$ at room temperature. Their average diameters were measured via light microscope (CiS, Nikon).

\section{Q-PCR quantification}

Ca-Alginate scaffolds were dissolved in $50 \mathrm{mM}$ EDTA solution at $37^{\circ} \mathrm{C}$ for $5 \mathrm{~min}$ and the cells were collected by brief centrifugation. Total RNA was extracted from human osteoblasts using Total RNA Miniprep Purification Kit (GeneMark) after 1, 7, 14 days' 3D culture as described in Section hOBs isolation and expansion. The total RNA was reverse-transcribed into complementary DNA (cDNA) by using Thermo Scientific First Strand cDNA Syn- thesis kit in accordance with the manufacturer's protocol. $5 \mu \mathrm{L}$ of $5 x$ OmicsGreen qPCR Master Mix (Omics), $10 \mu \mathrm{L}$ of primers (Additional File 1: Table S1), and $10 \mu \mathrm{L}$ of cDNA were mixed in a final volume of $25 \mu \mathrm{L}$ for single reaction. Beta-2 microglobulin (B2M, GenBank accession no. NM_004048) was used as the endogenous housekeeping gene. Genes examined were inducible type I collagen (Col1a1, GenBank accession no. NM_000088), alkaline phosphatase (Alpl, GenBank accession no. NM_001127501), runt-related transcription factor 2 (Runx2, GenBank accession no. BC108919.1), osteocalcin (Bglap, GenBank accession no. NM_000711). Reaction was performed by ABI PRISM 7500 Sequence Detection System (Life Technologies) and the PCR conditions were denaturation at $95^{\circ} \mathrm{C}$ for $10 \mathrm{sec}$, annealing at $60^{\circ} \mathrm{C}$ for $20 \mathrm{sec}$, and extension at $72{ }^{\circ} \mathrm{C}$ for $34 \mathrm{sec}$ for up to 40 cycles. The data of relative quantitation value of gene expression was calculated using the expression of $2^{-\Delta \Delta C t}$.

\section{Confocal microscope}

After being cultured for 14 days with perfusion, bone-like tissues in Ca-Alginate scaffolds were stained with $4 \mu \mathrm{M}$ calcein AM (Life Technologies Inc., CA, USA) for $30 \mathrm{~min}$ and the DNA in nucleus were stained with $1 \mu \mathrm{g} / \mathrm{ml}$ Hoechst 33342 (Life Technologies) for $5 \mathrm{~min}$. The nucleus were stained in blue fluorescence by Hoechst 33342 (ex/em $350 \mathrm{~nm} / \sim 461$ $\mathrm{nm})$, and cell bodies showed green fluorescence by calcein AM (ex/em $\sim 495 \mathrm{~nm} / \sim 515 \mathrm{~nm}$ ).

To perform biomineralization examination, bone-like tissues in Ca-Alginate scaffolds were fixed by $4 \%$ para-formaldehyde (Affymetrix). The calcified area of bone-like tissues were reacted with $20 \mu \mathrm{M}$ xylenol orange (Sigma-Aldrich) for $15 \mathrm{~min}$, and the counterstained with $1 \mu \mathrm{g} / \mathrm{ml}$ Hoechst 33342 for $5 \mathrm{~min}$. The calcified area would display in bright orange-red (ex/em $\sim 440 \mathrm{~nm} / \sim 610 \mathrm{~nm}$ ) by confocal microscope (LSM 780, Zeiss), and 3D cell images were reconstructed.

\section{D micro-computed tomography}

Before histological processing, total bone density and relative bone volume of bone-like tissues at Ca-Alginate scaffold were analyzed via a micro-CT instrument (SkyScan 1176, Bruker). Results of volumetric bone mass density (vBMD) were expressed in $\mathrm{mg} / \mathrm{cm}^{3}$. The data were reconstructed and showed in three dimensions.

\section{Statistical analysis}

Statistical analysis was conducted at least in triplicate, and all the results were presented as the mean \pm standard deviation (SD). Statistical analysis was performed for all the quantitative results using Student's t-test for comparing means from two inde- 
pendent sample groups. A difference of $p$ values less than 0.05 was considered statistically significant.

\section{Results}

Bioreactor systems are devices that support an active environment for cell/tissue growth. In this study, a functionally closed process bioreactor system was used as a model to create bone-like tissues (Fig. 1). Initially, hOBs were harvested from cancellous bone collected during surgery (Step 1, IRB No. 201012057RB). Osteoblasts could be cultured in a 2D environment under static conditions, but 2D culture might limit proliferative activity and cause loss of the osteoblastic phenotype (Step $2^{\prime}$ to $3^{\prime}$ ). Conversely, seeding of osteoblasts into Ca-Alginate scaffolds followed by incubation in a functionally closed process bioreactor system for 3D culture with perfusion could prevent loss of the cellular phenotype (Step 2 to 3). Ca-Alginate scaffolds exhibit a highly porous structure and provide a 'soft' growth environment for cell aggregation. After 7-14 days of incubation, a chelating reagent was used to breakdown the Ca-Alginate scaffolds and the resulting bone-like tissue collected by centrifugation (Step 4). Bone-like tissue generated with this protocol might be utilized for autologous bone transplantation (Step 5).

\section{Characterization of Ca-Alginate scaffolds and hOBs}

The Ca-Alginate scaffolds were fabricated with a freeze-drying technique (Fig. 2A). Cylindrical scaffolds $5 \mathrm{~mm}$ in height and $5 \mathrm{~mm}$ in diameter (weight: $10.1 \mathrm{mg}, 0.017 \mathrm{mMol}$ calcium, Table 1) were prepared. The porosity of this matrix exceeded $96 \%$, so that the surface area for cell/tissue expansion is larger in Ca-Alginate scaffolds than in 2D culture systems. The Brunauer-Emmett-Teller (BET) surface area by nitrogen adsorption method was $4.00 \pm 0.21 \mathrm{~m}^{2} \bullet \mathrm{g}^{-1}$ and the Langmuir surface area was $6.56 \pm 0.74 \mathrm{~m}^{2} \bullet \mathrm{g}^{-1}$ (Table 1).

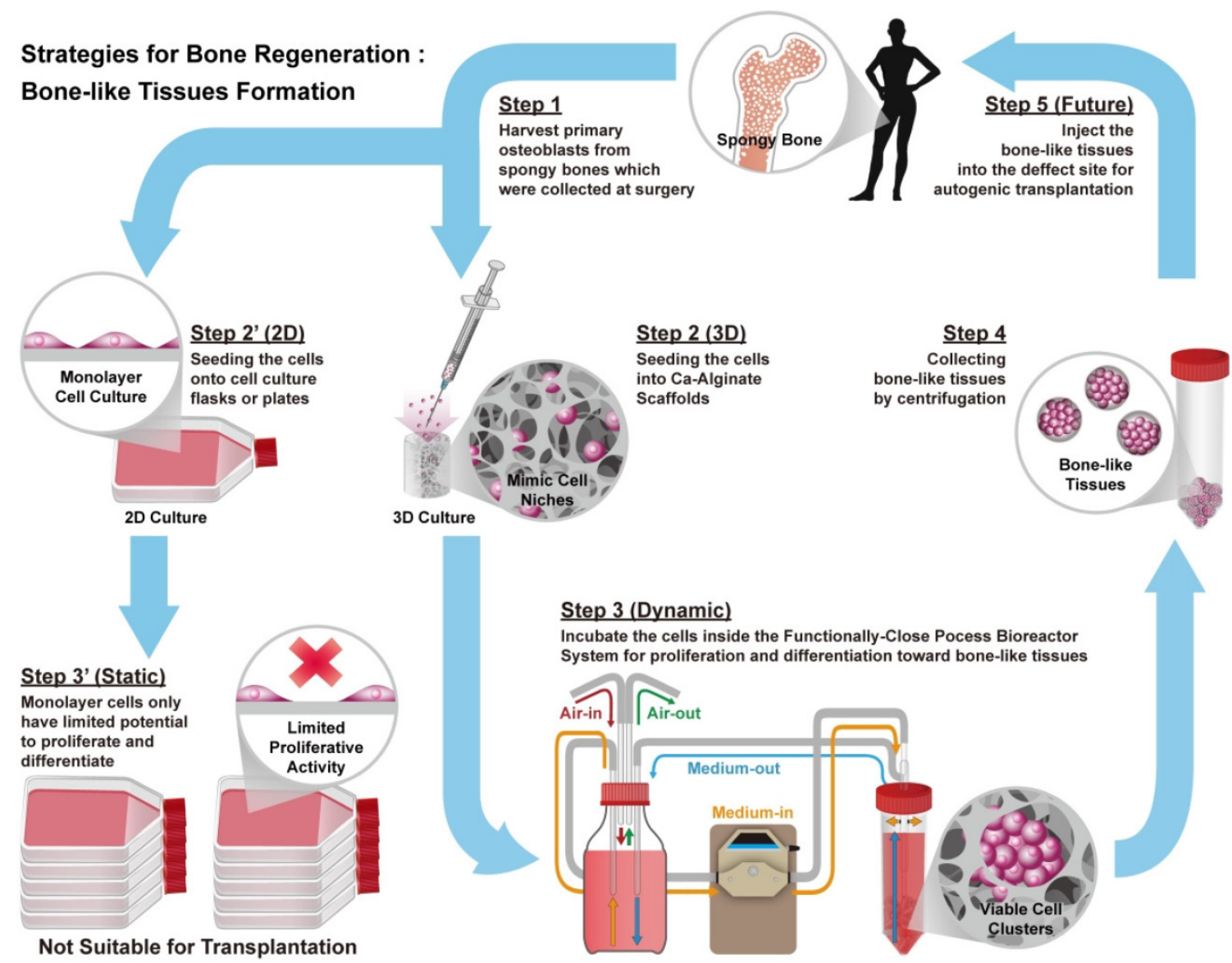

Figure 1. Schematic illustrations of the general concept and strategy for this study. Briefly, step 1 is to harvest human osteoblasts from cancellous bones which were collected at surgery (Step 1). Next step is to culture cells at 2D environment with static condition, which might limit proliferative activity and loose phenotype (Step 2' to Step 3'). Instead, employ Ca-Alginate scaffolds as cell culture matrices and incubate these cells at the functionally-closed process bioreactor system with dynamic fluid (Step 2 to Step 3). At the end of incubation, extract these bone-like tissues without any enzymatic treatment (Step 4). In the future, the bone-like tissues could apply to autogenic transplantation and provide customized patient safety (Step 5). 

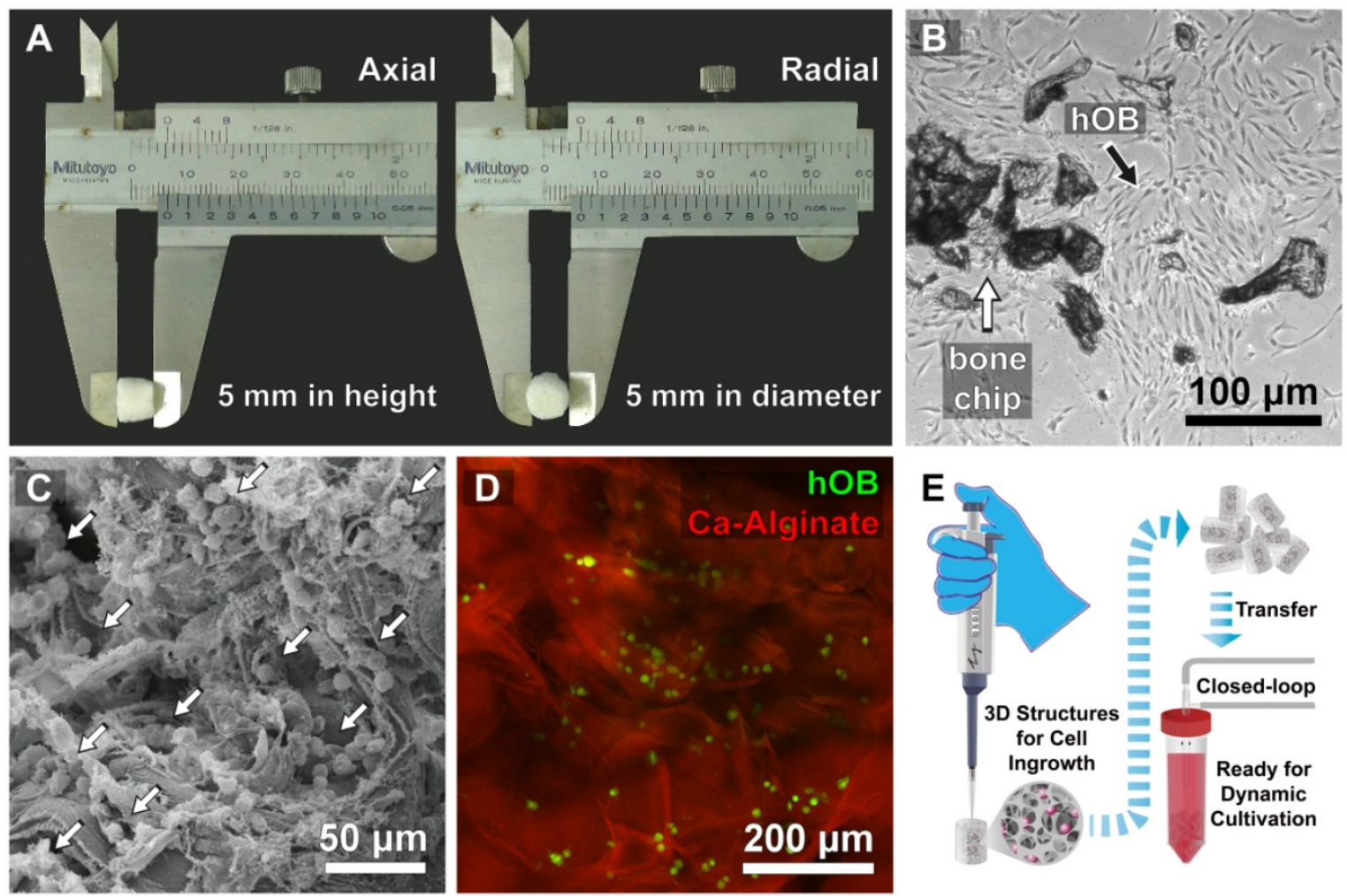

Figure 2. Characterization of Ca-Alginate Scaffolds and hOBs. (A) The Ca-Alginate scaffold was in cylinder-shaped and $5 \mathrm{~mm}$ in height and $5 \mathrm{~mm}$ in diameter; (B) hOBs (black arrow) were derived from bone chips (white arrow) which were digested by type I collagenase; (C) hOBs (white arrow) seeding in the Ca-Alginate scaffold was observed by scanning electronic microscope; (D) hOBs stained in green (CFSE dye) and were dispersed in the Ca-Alginate scaffold; (E) showed the illustration of cell seeding process.

hOBs derived from bone chips pre-digested with collagenase type I were harvested (Fig. 2B) and seeded into the Ca-Alginate scaffold (Fig. 2C). Since alginate is a polysaccharide and could be stained by safranin $\mathrm{O}$, hOBs were stained with a carboxyfluorescein diacetate succinimidyl ester (CFSE) dye and we found that hOBs were dispersed in a homogeneous pattern (Fig. 2D), and the 3D structural illustration was provided in Additional File 2: Video S1. To mimic the individual variability of human physiolo-

Table 1. Characterization of Ca-Alginate Scaffolds

\begin{tabular}{|c|c|c|c|}
\hline \multicolumn{4}{|c|}{ (I) $\mathrm{Ca}^{2+}$ Concentration of Ca-Alginate Scaffolds } \\
\hline & Weight (mg/scaffold & & $\mathrm{Ca}^{2+}(\mathrm{mMol})$ \\
\hline \multicolumn{3}{|c|}{$10.1 \pm 1.0$} & $0.017 \pm 0.006$ \\
\hline \multicolumn{4}{|c|}{ (II) Porosity of Ca-Alginate Scaffolds } \\
\hline \multirow{2}{*}{\multicolumn{3}{|c|}{ Ca-Alginate Scaffolds (Freezed-Dry) }} & Porosity \\
\hline & & & $\sim 96.46 \%$ \\
\hline \multicolumn{4}{|c|}{ (III) Surface Area of Ca-Alginate Scaffolds } \\
\hline & & Sureface Area & Correlation Coefficient \\
\hline & BET Surface Area & $4.00 \pm 0.21 \mathrm{~m}^{2} / \mathrm{g}$ & 0.998 \\
\hline & Langmuir Surface Area & $6.56 \pm 0.74 \mathrm{~m}^{2} / \mathrm{g}$ & 0.994 \\
\hline
\end{tabular}

gy, all cells were cultured in a custom bioreactor system (Fig. 2E).

\section{Doubling time and seeding efficiency of hOBs}

To determine growth rates of hOBs, alamar blue was be used for estimating the cell doubling time (Fig. $3 \mathrm{~A})$. Initially, we investigated cell growth in the presence or absence of osteogenic signals in a 2D environment. This analysis revealed that cell doubling time without osteogenic induction treatment was about 87 hours, whereas cell doubling time was about 125 hours in the presence of osteogenic signals. Initial cell density was 500,000 cells/scaffold and cell seeding efficiency was about $69 \%$ (Fig. 3B). The aim of our research was to provide a suitable environment for the formation of functional bone-like tissues. Therefore, cells cultured in 3D were exposed to osteogenic signals and dynamic fluid flow. All the data collected under 3D conditions was normalized to cell seeding efficiency. After the initial 7 days of culture, cell proliferation almost stopped, whereas in the final 7 days, the cells expanded and the doubling time was shortened to 132 hours. 
A

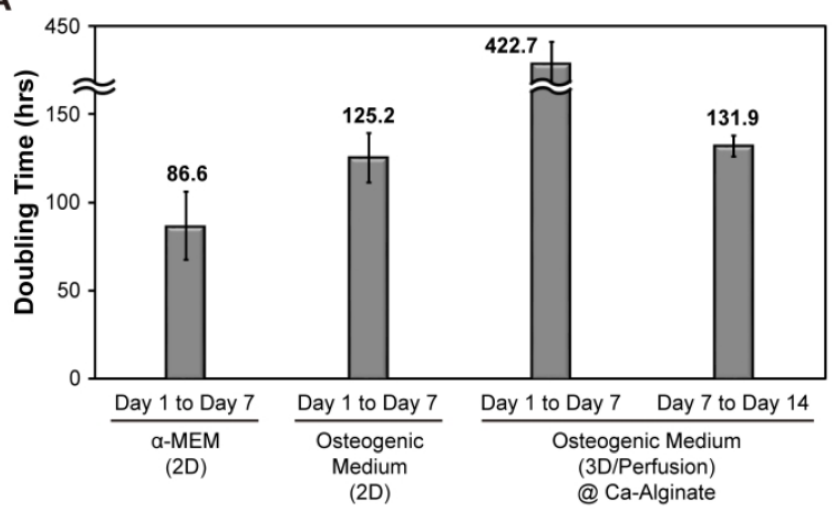

B

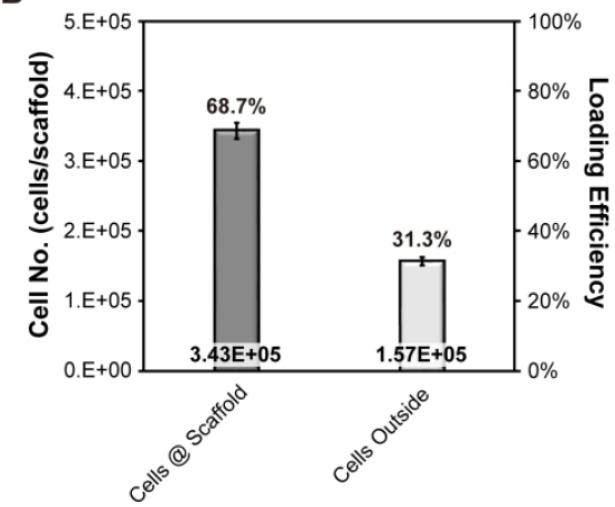

Figure 3. Doubling time and seeding efficiency of hOBs. (A) The doubling time of hOBs at 2D and 3D condition; (B) the cell seeding efficiency.

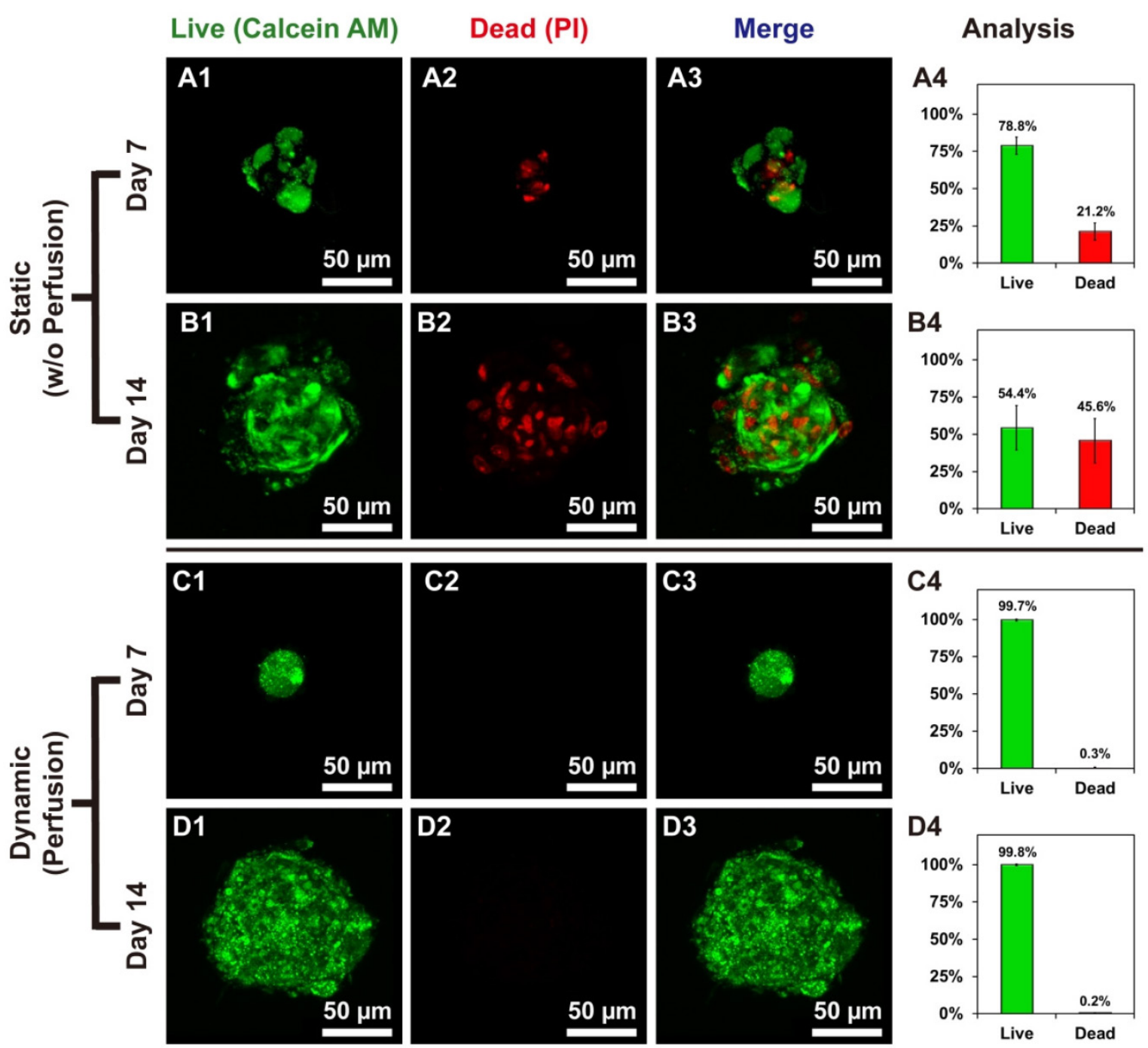

Figure 4. Live/dead staining showed the difference between hOBs @Ca-Alginate scaffolds w/ and w/o perfusion. (A1, B1, C1, and D1) in green represented the live cells of bone-like tissues with calcein AM dye; (A2, B2, C2, and D2) in red (PI) indicated dead cells; (A3, B3, C3, and D3) were the merge images; (A4, B4, C4, and D4) displayed the percentage of live and dead cells.

\section{Live/Dead staining of bone-like tissues in Ca-Alginate scaffolds}

Cell viability of bone-like tissues within Ca-Alginate scaffolds was determined by staining with two-color fluorescent dyes (Calcein AM/PI). Static conditions might cause death of human osteoblasts in 3D environment (Fig. 4A and 4B), whereas hOBs survived in Ca-Alginate scaffolds with dynamic fluids (Fig. 4C and 4D). In the static group, $21.2 \%$ of 
total cells were dead inside cell clusters at day 7 and $45.6 \%$ of total cells was stained with red fluorescence at day 14. Cell death was localized at the center of cell clusters, and all the 3D corresponding animated movies were provided in Additional File 2 (Video S2, S3, S4, and S5). Conversely, most cells in the dynamic group were stained in green and less than $1 \%$ of total cells died both at day 7 and day 14 . Consequently, Ca-Alginate scaffolds could create an environment permissive for hOBs ingrowth and cell clusters formation and the perfusion system played a pivotal role in maintaining cell viability.

\section{SEM morphology and EDX Analysis}

The morphology of hOBs in Ca-Alginate scaffolds was revealed by scanning electron microscopy (SEM), and the calcium/phosphorous signals were detected by SEM with energy dispersive X-ray spectroscopy (SEM/EDX, Fig. 5). The SEM images showed that individual cells were embedded within the Ca-Alginate scaffolds on day 1 , and only calcium signal from scaffolds were detected through the SEM/EDX measurement (Fig. 5A1 and 5A2). Under dynamic perfusion, hOBs proliferated and by day 7 aggregated into cell clusters that could secrete and amplify large quantity of ECM (Fig. 5B1 and 5B2). At day 14, large cell clusters were surrounded by ECM, and the EDX data indicated that a layer of apatite of biological origin was formed at the surface (Fig. 5C1 and 5C2). These hOBs cell clusters presented 3D structures and exhibited osteogenic functions, such as mineralization, suggesting that Ca-Alginate scaffolds integrated with the perfusion system provide a suitable environment for bone-like tissue formation.

\section{Size distribution of bone-like tissues}

The size distribution of bone-like tissues was assessed using light microscopy, and data calculated with MetaMorph software (Molecular Devices, CA, USA). Nearly half of cell clusters were under $50 \mu \mathrm{m}$ in size at Day 7, but over $60 \%$ of cell clusters were higher than $100 \mu \mathrm{m}$ in size at Day 14 (Fig. 5D), proving that hOBs would self-aggregate and proliferate in a $3 \mathrm{D}$ environment under dynamic conditions.

Most bone-like tissues exhibited a round or elliptical shape (Fig. 5E), and the animation of bone-like tissues including $3 \mathrm{D}$ reconstruction and cross-section was provided in Additional File 2 (Video S6). Considering that most cell clusters were smaller than 200 $\mu \mathrm{m}$ in size, the bone-like tissues produced from this system were injectable. In summary, these results demonstrated that the bone-like tissues generated in our custom bioreactor system are appropriate for surgical applications.

\section{mRNA expression levels of bone-like tissues}

Ca-Alginate scaffolds were dissolved in a $50 \mathrm{mM}$ EDTA solution at $37^{\circ} \mathrm{C}$ for 5 min at Day 7 and 14 . To determine osteoblastic differentiation in the 3D cultures, expression of osteoblast gene markers was measured by real-time quantitative polymerase chain reaction (Q-PCR). Col1a1 encodes for a major structural component of the bone ECM. Alpl encodes for a hydrolase enzyme highly expressed in bone that increases during bone formation. Runx2 (also known as $C b f a 1)$ encodes for a transcription factor required for osteogenic differentiation, and Bglap encodes for osteocalcin (OC), a secreted molecule that acts as a hormone that stimulates bone formation. All data for gene expression was normalized by control group (monolayer hOBs cultured without osteogenic induction) and calculated using the expression of $2^{-\Delta \Delta C t}$. A general upregulation in the expression of osteoblastic markers, which became more pronounced as the culture progressed, was observed (Fig. 6A to 6D). These results indicate that use of Ca-Alginate scaffolds in the bioreactor system favors osteoblastic differentiation.

In order to determine the efficacy of the bioreactor, we also evaluated osteoblastic mRNA levels, which performed by hOBs to tissue culture plastic (2D culture group), by hOBs to Ca-Alginate scaffold alone (3D static condition). As shown in live/dead staining, there were large amounts of cells died in 3D static group and lead to difficulty in purifying total RNA; therefore, we could not get enough quality and quantity of total RNA for Q-PCR experiments. For 2D culture group, monolayer cells was allowed to adhere on tissue culture plastic and supplied with osteogenic medium. A comparison between 2D static and 3D dynamic cultivation with osteogenic induction at different time period was presented in Additional File 1: Fig. S1A to S1D. The values of target gene expression were compared with control group (Ctrl). Although all the osteogenic markers upregulated as time goes by, Alpl, Runx2 and Bglap genes showed greater increase in $3 \mathrm{D}$ group from this data; there was no significant difference between $2 \mathrm{D}$ and $3 \mathrm{D}$ group in Col1a1 mRNA levels.

\section{Biomineralization of bone-like tissues}

Xylenol orange $(\mathrm{XO})$ is a fluorochrome specific for calcified tissues. After 14 days of perfusion, the calcified area of bone-like tissues was stained with XO (Fig. 6E to $6 \mathrm{H}$ ). There were significant signals displayed on Fig. $6 \mathrm{E}$, and the Fig. $6 \mathrm{~F}$ represented the nucleus location. Under visible light, the bone-like tissue embedded within the Ca-Alginate scaffold could be observed in its entirety. These results suggest that Ca-Alginate scaffolds and dynamic osteogenic supplements might provide a suitable environment 
for hOBs to regulate bone mineralization. According to the data of SEM morphology, Q-PCR analysis and biomineralized measurement, these bone-like tissue could preserve osteogenic tissue function and be utilized via injective technique (showed in Additional File 1: Fig. S1E).

Figure 5. The morphology and size distribution of bone-like tissues. (A to $\mathrm{C}$ ) The morphology of hOBs @ Ca-Alginate scaffolds were examined by SEM under 350x observation; through the EDX determination, the calcium and phosphorous ions increase over time; $(\mathrm{Al}$ to $\mathrm{Cl})$ the images were under 1000x observation; (D) showed the size distribution of bone-like tissues after 7 and 14 days perfusion. The third part was confocal images of the bone-like tissue after 14 days perfusion. (EI) in green indicated the cell bodies of bone-like tissue with calcein AM dye; (E2) in blue with Hoechst 33342 revealed the nucleus location; (E3) was the fluorescent merge image; (E4) showed the z-axis; (E5) displayed the bone-like tissue within Ca-Alginate scaffold in bright field; (E6) was the merge image of the bone-like tissue within Ca-Alginate scaffold.
SEM
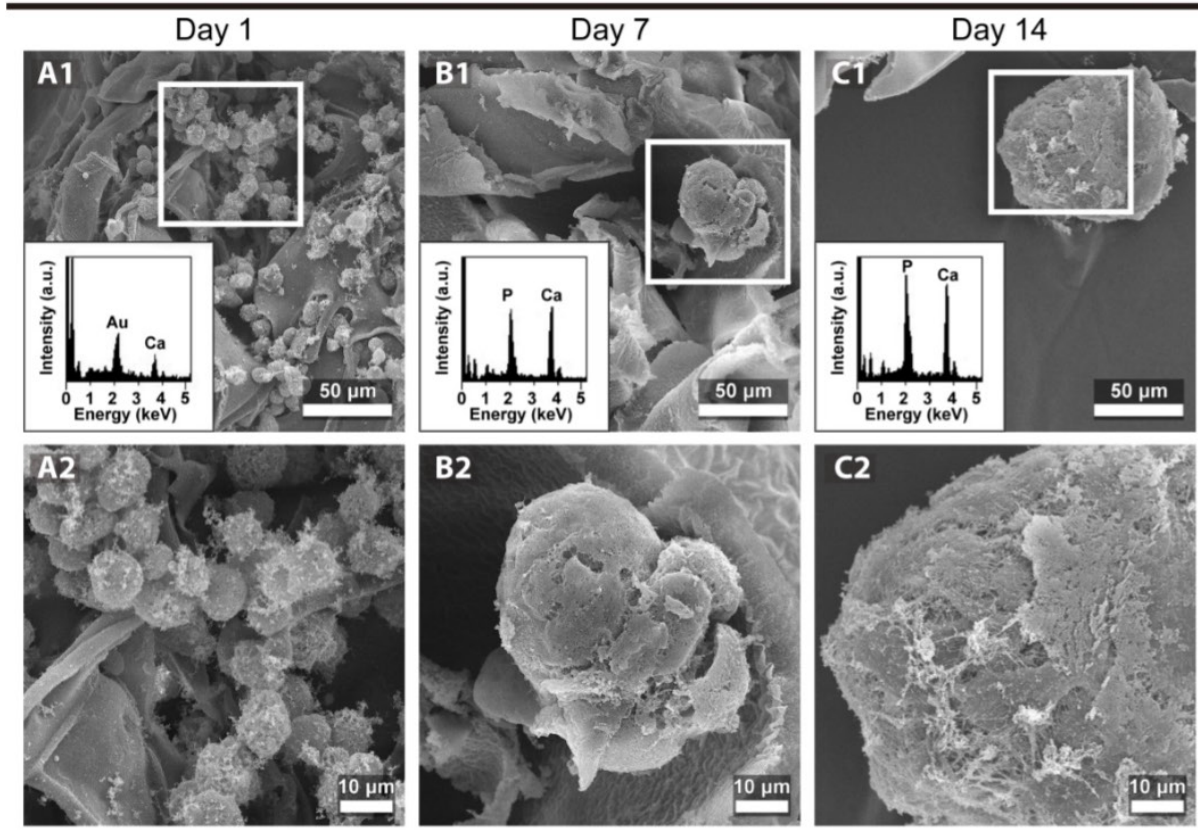

\section{Cell Cluster Size Distribution}

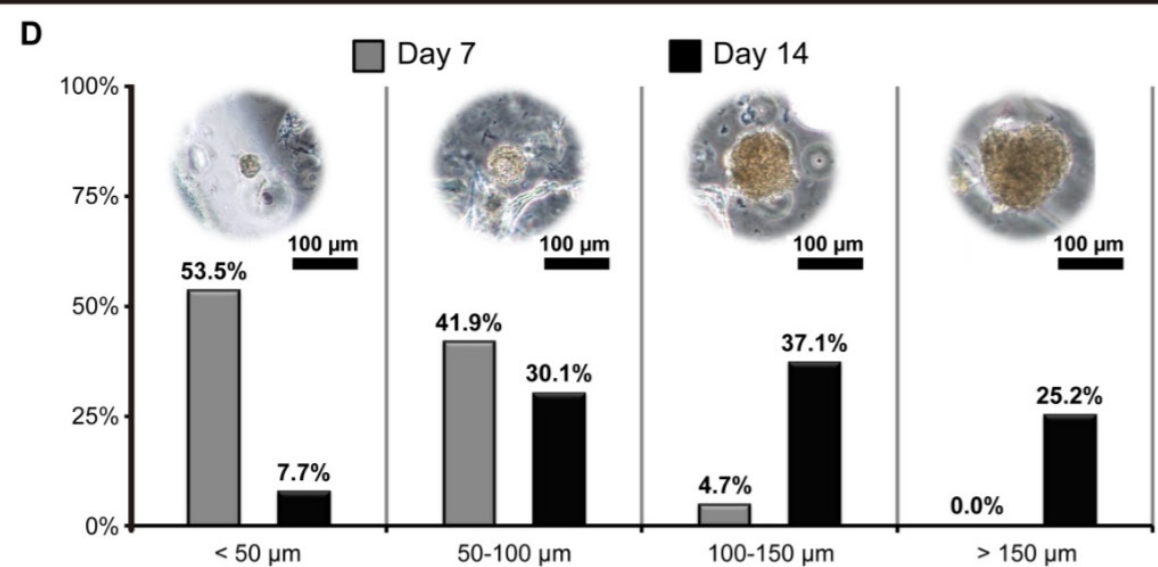

Injectable Bone-like Tissue
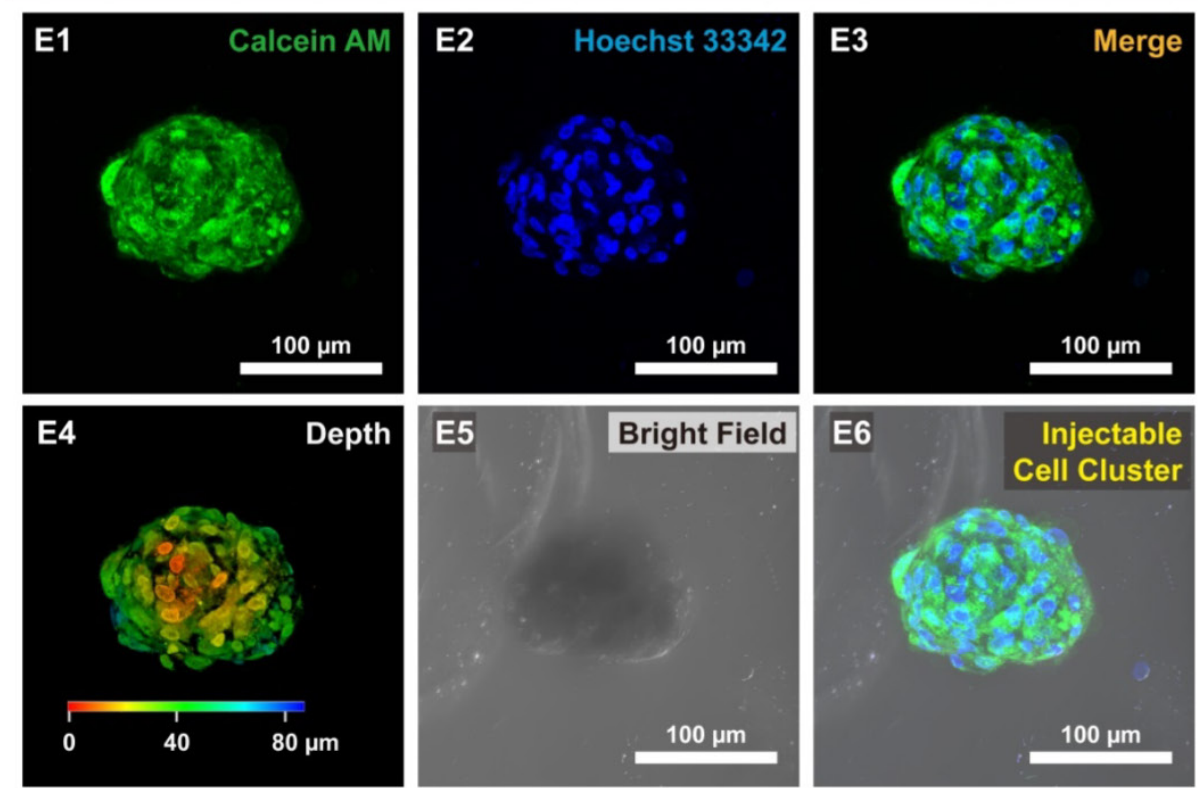


\section{Volumetric bone mass density and bone vol- ume}

Volumetric bone mineral density (vBMD) and bone volume fraction (BV/TV) were quantified by micro-computed tomography (micro-CT) at a $9-\mu \mathrm{m}$ isotropic voxel size resolution in Ca-Alginate containing bone-like tissues at day 7 and day 14. 3D reconstructions were obtained by stacking 2D images, and 3 regions of interest were chosen randomly from the full view of Ca-Alginate scaffolds for analysis (Fig. $6 \mathrm{I}$ and $6 \mathrm{~J})$. BV/TV was calculated using the algorithm provided in the supplied software (CTvox 2.4, Bruker, Belgium) and expressed as percentages (\%). After 7 and 14 days of perfusion, vBMD and bone volume fraction increased (Fig. $6 \mathrm{~K}$ and $6 \mathrm{~L}$ ), suggesting that the bone-like tissues obtained with the technique described in this study have the potential to be used in therapeutic applications of bone tissue engineering.
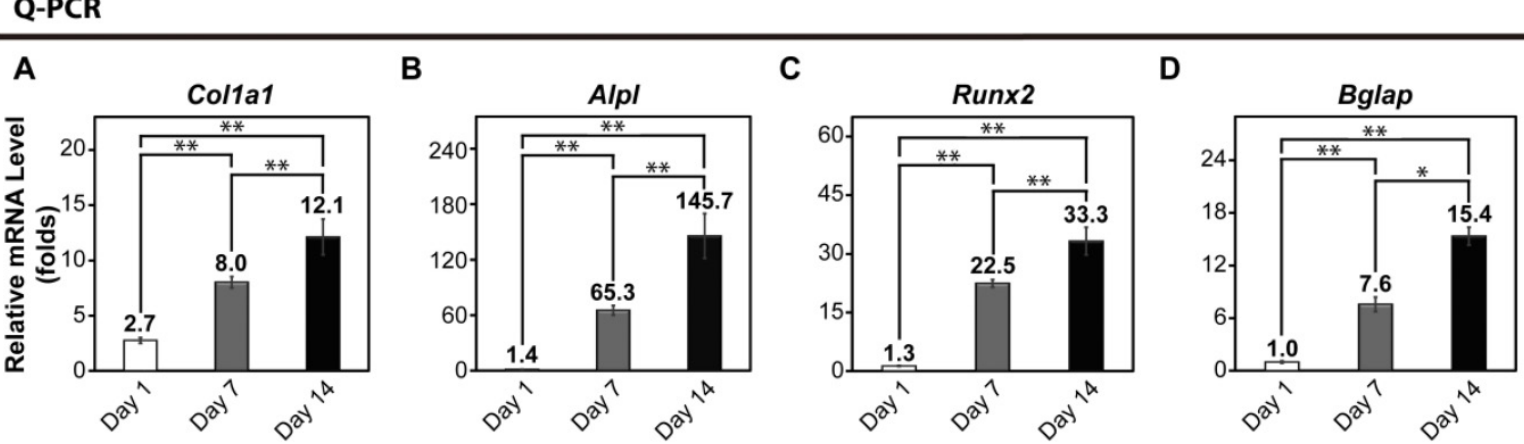

Biomineralization (Confocal Microscopy)
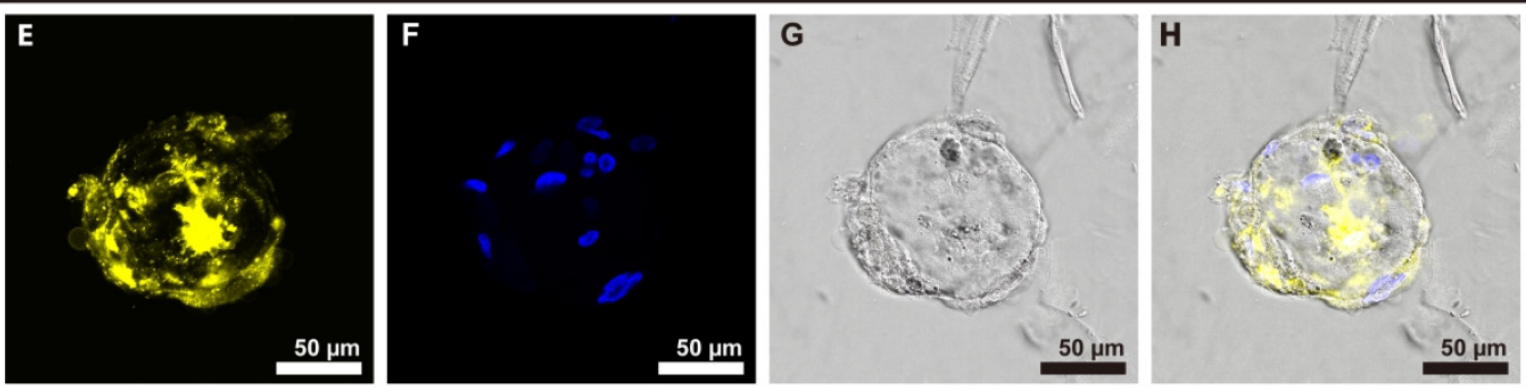

\section{Biomineralization (Micro-CT)}
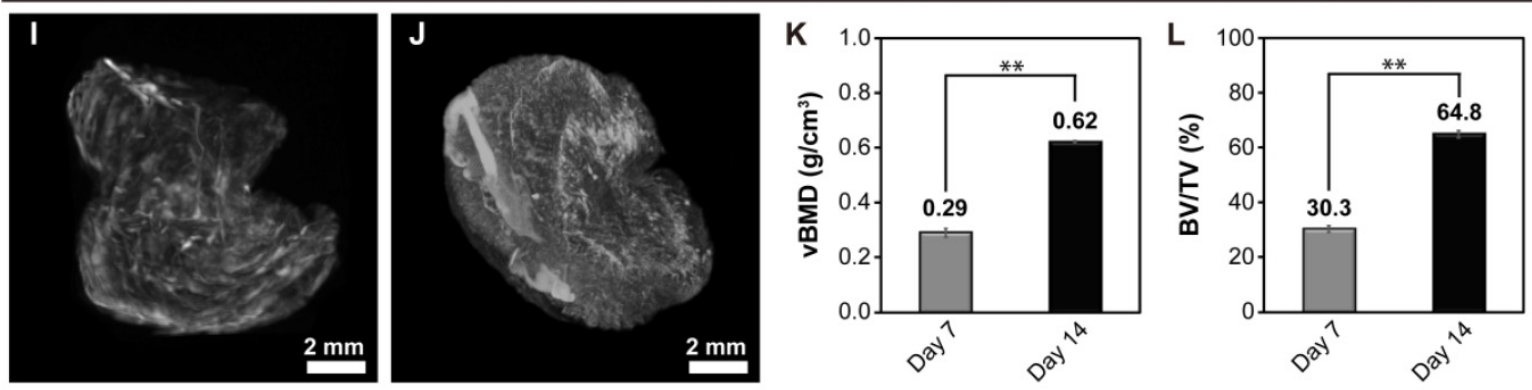

Figure 6. Bone-related gene expression and biomineralization of the bone-like tissues. (A to D) At Day 1, hOBs were seeded into Ca-Alginate scaffolds and kept in static state to stabilize cells in 3D environment for 24 hours. After 7 and 14 days perfusion, the tissues were collected for gene expression examination. Expression of (A) Collal; (B) Alpl; (C) Runx2; and (D) Bgalp were increased by time. For all the Q-PCR experiments, the relative mRNA level was calculated following $\triangle \triangle$ Ct method, and each target gene was normalized to control group (monolayer cells cultured without osteogenic induction). The Q-PCR values were mean \pm SD; ${ }^{*}$ < 0.05 , ${ }^{* *} \mathrm{p}<0.01(\mathrm{n}=6)$. $(\mathrm{E}$ to $\mathrm{H})$ Confocal images of the biomineralization. The confocal images of the biomineralization taken after 14 days perfusion, the calcified area of bone-like tissues. (E) In yellow indicated the calcified area of bone-like tissues with xylenol orange; (F) in blue with Hoechst 33342 revealed the nucleus location; $(\mathrm{G})$ was the merge image; $(\mathrm{H})$ displayed the morphology at bright field. (I to $\mathrm{L}$ ) After 7 and 14 days perfusion, micro-CT analysis were representative of $n=3$ samples. (I) 3D reconstruction image on Day7; (J) 3D reconstruction image on Dayl4; (K) the relative volumetric bone mass density (vBMD) ; (L) the relative bone volume (BV/TV). The values of the relative volumetric BMD and the relative bone volume were mean \pm SD; **p $<0.01$, compared to Day 7 group.

\section{Discussion}

Several factors in the cellular microenvironment and in the stem cell niche influence cell fate; soluble factors, such as growth factors and cytokines, nutrients and bioactive molecules; cell-cell interactions; cell-biomaterial interactions; physical factors, such as the rigidity of the substrate. Biomaterials that mimic the cell microenvironment and the conditions found in the stem cell niche facilitate the production of large numbers of differentiated cells needed for in vitro regenerative medicine [29]. The ultimate goal of regen- 
erative medicine is to develop fully functioning bioengineered organs able to work in cooperation with surrounding tissues to replace organs that were lost or damaged as a result of disease, injury or aging. It is anticipated that bioengineering technology will allow the reconstruction of fully functional organs in vitro through the precise arrangement of several different cell types [4]. To achieve the functional replacement of lost or damaged tissues and organs, the development of 3D bioengineered tissues comprising a single cell type was attempted in this study.

We successfully established a platform for human osteoblast cell clusters production for bone tissue reconstruction. Autogenic bone transplantation is still the golden standard of bone regeneration [30]. With increasing age, there is not only a significant reduction in bone formation, but also a loss of bone mass and strength. [31]. The reconstruction of large bone defects is the major challenge in the field of orthopedic surgery and bone graft transplantation [11, 32] is the only possible avenue of intervention, especially in the elder population. Hence, functional osteogenic cell constructs have the potential to be used to correct large bone defects.

In this study, we chose human osteoblasts as the cell source for autologous transplantation. Cell proliferation is necessary for tissue growth and regeneration [33], but long-term culture of primary cells in monolayer might lead to loss of phenotype and impaired growth [34]. To overcome these limitations, 3D culture platforms such as highly porous, biomimetic scaffolds were developed to increase cell differentiation efficiency. However, little is known about the effects of 3D culture condition on mesenchymal stem cell (MSC) differentiation. Furthermore, it is difficult to obtain a reproducible design of synthetic biomaterial-based scaffold environments able to control cell-cell, cell-ECM, and cell-biomaterial interactions. This is due to inability to obtain a uniform cell seeding density and architecture, as well as mechanical and surface properties of the scaffold materials. In this study, we chose highly porous Ca-Alginate scaffolds generated by a freeze-drying technique to create a structure for nutrient transportation. Ca-Alginate can form a hydrogel-like structure to keep cells in a moist environment and provide the high calcium ion concentrations required for osteogenic differentiation. Application of 3D cell culture techniques is gaining interest due to evidence showing significant differences between the cellular phenotype and biological response of cells between monolayer and 3D cultures. The 3D structure facilitates more extensive cell-cell contacts and interactions of cells with the ECM, allowing cells to achieve their native morphology and possibly by influencing signaling activity. Subse- quently, it is increasingly accepted that 3D culture methods provide a cellular environment that resemble the in vivo conditions more closely [35]. To improve and preserve cell function, we created a 3D culture model. According to previous studies, cell scaffolds can be classified as either preformed or injectable. Preformed scaffolds exhibit a highly porous structure that favors nutrient transportation and cell migration. Injectable scaffolds, such as hydrogels, can adapt to the shape of the defect site but due to the dense structure, injectable scaffolds can quench cells but might block nutrient transportation. The Ca-Alginate scaffold used in this study share characteristics of both preformed and injectable scaffolds. It presents a highly porous structure for nutrient transport and offered numerous surface area for hOBs ingrowth. It also forms hydrogel-like structures that keep cells in a moist environment. For bone tissue engineering applications, a scaffold with high porosity and suitable pore size is indispensable for directing osteogenesis. In addition, Ca-Alginate scaffolds contained a high amount of smaller pores that restrict the available volume for cell ingrowth, and force cells to aggregate in clusters [36]. It was reported that alginate with calcium divalent cations crosslinks might enhance cells/tissues mineralization in biomedical applications [37-39]. In this study, expression of osteoblast gene markers and mineralization were upregulated by osteogenic induction, indicating that the Ca-Alginate scaffold could provide an appropriate microenvironment for cell clusters ingrowth and differentiation. Even though the Q-PCR data showed a similar tendency toward osteogenic differentiation in 2D static and 3D dynamic groups at different time period; bone-like tissue formation in the self-designed bioreactor system preserved osteogenic tissue function with proper size/shape for injection (showed in Additional File 1: Fig. S1E).

Under static culture conditions, bone marrow stromal cells in large cell scaffold or constructs would exhibit decreased proliferation and inhibited expression of osteogenesis-related proteins [40]. Moreover, when the diffusion distance exceeds 100-200 $\mu \mathrm{m}$, the homogeneous transport of gas and soluble nutrients becomes a critical obstacle for cell culture under static conditions [41]. Providing sufficient oxygen and nutrient exchange to engineered tissue constructs larger than $100 \mu \mathrm{m}$, selecting a suitable cell type and creating a matrix with a complex architecture to support the tissue are key challenges for organ engineering. A 3D scaffold mimicking the natural extracellular environment has great potential for tissue engineering applications [42]. In this study, we utilized 3D porous Ca-Alginate scaffolds coupled with a functionally closed bioreactor system as an approach for bone re- 
generation. A bioreactor with a closed loop system is appropriate for current good manufacturing practices (cGMP) and reduces the risk of contamination [8].

Osteoblasts are capable of self-renewal and differentiation along the osteogenic lineage and have potential for therapeutic applications. Therefore, we developed a 3D techniques for in vitro osteoblasts culture using alginate scaffold and a close-system bioreactor. Our results showed that under optimal conditions, osteoblasts form compact cellular spheroids and remain viable in 3D culture. Overall, this work suggests a novel therapeutic application for dynamic 3D osteoblast cultures and presents a viable alternative to monolayer culture techniques. We report that, when cultured in the functionally-closed process bioreactor system under osteogenic induction, hOBs can self-aggregate as bone-like cell clusters within Ca-Alginate scaffolds and achieve a mature phenotype characteristic of bone tissue. Henceforth, all procedures can be performed with ease under cGMP conditions to manufacture bone-like tissues and for their application from bench to bedside. However, the information on osteoblasts mechanosensitive response to biomechanical cues in $3 \mathrm{D}$ in vitro microenvironments is still sparse and further study to define the optimal parameters of 3D-fluid flow-mediated biomechanical stimulation in perfusion bioreactors is warranted.

The application of cells in bone tissue engineering and regenerative medicine requires the development of suitable bioprocesses. Ideally, these processes should facilitate the integrated, reproducible and automatable production of clinically-relevant, scalable and integrated bioprocesses to generate sufficient cells for the formation of $3 \mathrm{D}$ bone tissue-like constructs [18]. In this study, we developed a functionally closed process bioreactor system in combination with Ca-Alginate scaffolds. For the purpose of cell therapy, reproduction of the conditions found in the cell niche in vivo is a key factor to maintain cell functionality. In the bioreactor system described in this work, hOBs could ingrowth, differentiate into mineralizing cells and produce bone-like tissues. Consequently, this bioprocess promises to provide an efficient, automatable, scalable and functional culture system for applications in bone tissue engineering requiring macroscopic bone formation. This strategy could produce enough bone-like tissues for cell therapy and avoid the side effects of allograft or xenograft transplants. In conclusion, the functionally closed process bioreactor system developed by our laboratory could provide a safe and affordable tool for bone tissue engineering.

\section{Conclusion}

In this study, we had developed a functionally-closed process bioreactor system and combining Ca-Alginate scaffolds. For the purpose on cell therapy, mimic cell niche in vivo is a key mediator of maintaining cell capability. Under osteogenesis in the self-made bioreactor system, hOBs could ingrowth and differentiate into bone-like tissues with biomineralization. This strategy could make up enough bone-like tissues for cell therapy and avoid the side effects from allograft or xenograft. Overall, the results demonstrate that the functionally-closed process bioreactor system could provide a safe and economic tool on bone tissue engineering.

\section{Supplementary Material}

Additional File 1: Figure S1, Table S1.

http://www.thno.org/v05p0643s1.pdf

Additional File 2: Video S1-S6.

http://www.thno.org/v05p0643s2.pptx

\section{Acknowledgements}

We thank Mr. Yu-Tung Chen for schematic drawing. Also the authors acknowledge the staff of First Core Lab (Collage of Medicine, NTU) and many colleagues of the Second Core Lab (Department of Medical Research, NTUH) for technical support and helpful discussions. This work was supported by a grant from the Ministry of Science and Technology (NSC 100-2221-E-002-140), Taiwan, Republic of China. The procedure in this study has been approved by the Internal Ethical Committee of National Taiwan University Hospital, Taiwan (IRB No. 201012057RB).

\section{Competing Interests}

The authors have declared that no competing interest exists.

\section{References}

1. Langer R, Vacanti J. Tissue engineering. Science. 1993; 260: 920-6.

2. Walgenbach K-J, Voigt M, Riabikhin AW, Andree C, Schaefer DJ, Galla TJ, et al. Tissue engineering in plastic reconstructive surgery. The Anatomical Record. $2001 ; 263: 372-8$

3. Kim K, Evans G. Tissue engineering: the future of stem cells. Topics in tissue engineering. 2005; 2: 1-21.

4. Ikeda E, Morita R, Nakao K, Ishida K, Nakamura T, Takano-Yamamoto T, et al. Fully functional bioengineered tooth replacement as an organ replacement therapy. PNAS. 2009; 106: 13475-80.

5. Purnell B. New Release: The Complete Guide to Organ Repair. Science. 2008; 322: 1489

6. Griffith LG, Naughton G. Tissue Engineering--Current Challenges and Expanding Opportunities. Science. 2002; 295: 1009-14.

7. Brooks P. The burden of musculoskeletal disease - a global perspective. Clin Rheumatol. 2006; 25: 778-81.

8. Rauh J, Milan F, Gunther KP, Stiehler M. Bioreactor systems for bone tissue engineering. Tissue Eng Part B Rev. 2011; 17: 263-80.

9. Zhang YB, Zhong ZM, Hou G, Jiang H, Chen JT. Involvement of Oxidative Stress in Age-Related Bone Loss. J Surg Res. 2011; 169: e37-e42.

10. Sun JS, Chen PY, Tsuang YH, Chen MH, Chen PQ. Vitamin-D Binding Protein Does Not Enhance Healing in Rat Bone Defects: A Pilot Study. Clin Orthop Relat Res. 2009; 467: 3156-64.

11. Huey DJ, Hu JC, Athanasiou KA. Unlike Bone, Cartilage Regeneration Remains Elusive. Science. 2012; 338: 917-21. 
12. Schubert T, Lafont $S$, Beaurin G, Grisay G, Behets $C$, Gianello P, et al Critical size bone defect reconstruction by an autologous $3 \mathrm{D}$ osteogenic-like tissue derived from differentiated adipose MSCs. Biomaterials. 2013; 34: 4428-38.

13. Wang W, Itaka K, Ohba S, Nishiyama N, Chung UI, Yamasaki Y, et al. 3D spheroid culture system on micropatterned substrates for improved differentiation efficiency of multipotent mesenchymal stem cells. Biomaterials. 2009; 30: 2705-15.

14. Lund AW, Yener B, Stegemann JP, Plopper GE. The natural and engineered 3D microenvironment as a regulatory cue during stem cell fate determination. Tissue Eng Part B Rev. 2009; 15: 371-80.

15. Lee KY, Mooney DJ. Alginate: Properties and biomedical applications. Prog Polym Sci. 2012; 37: 106-26.

16. Draget KI, Smidsrød O, Skjåk-Bræk G. Alginates from Algae. In: Biopolymers Online. Weinheim: Wiley-VCH Verlag GmbH \& Co. KGaA; 2005: 1-30.

17. Sun JY, Zhao X, Illeperuma WRK, Chaudhuri O, Oh KH, Mooney DJ, et al. Highly stretchable and tough hydrogels. Nature. 2012; 489: 133-6.

18. Hwang YS, Cho J, Tay F, Heng JYY, Ho R, Kazarian SG, et al. The use of murine embryonic stem cells, alginate encapsulation, and rotary microgravity bioreactor in bone tissue engineering. Biomaterials. 2009; 30: 499-507.

19. Pawar SN, Edgar KJ. Alginate derivatization: A review of chemistry, properties and applications. Biomaterials. 2012; 33: 3279-305.

20. Rowley JA, Madlambayan G, Mooney DJ. Alginate hydrogels as synthetic extracellular matrix materials. Biomaterials. 1999; 20: 45-53.

21. Shull KR. Materials science: A hard concept in soft matter. Nature. 2012; 489: 36-7.

22. Leslie SK, Cohen DJ, Sedlaczek J, Pinsker EJ, Boyan BD, Schwartz Z. Controlled release of rat adipose-derived stem cells from alginate microbeads. Biomaterials. 2013; 34: 8172-84

23. Kuo CK, Ma PX. Ionically crosslinked alginate hydrogels as scaffolds for tissue engineering: Part 1 . Structure, gelation rate and mechanical properties. Biomaterials. 2001; 22: 511-21.

24. Awad HA, Quinn Wickham M, Leddy HA, Gimble JM, Guilak F. Chondrogenic differentiation of adipose-derived adult stem cells in agarose, alginate, and gelatin scaffolds. Biomaterials. 2004; 25: 3211-22.

25. Hunt NC, Smith AM, Gbureck U, Shelton RM, Grover LM. Encapsulation of fibroblasts causes accelerated alginate hydrogel degradation. Acta Biotechnol. 2010; 6: 3649-56.

26. Higuchi A, Ling Q-D, Ko Y-A, Chang Y, Umezawa A. Biomaterials for the Feeder-Free Culture of Human Embryonic Stem Cells and Induced Pluripotent Stem Cells. Chem Rev. 2011; 111: 3021-35.

27. Shapiro L, Cohen S. Novel alginate sponges for cell culture and transplantation. Biomaterials. 1997; 18: 583-90.

28. Lin YJ, Yen CN, Hu YC, Wu YC, Liao CJ, Chu IM. Chondrocytes culture in three-dimensional porous alginate scaffolds enhanced cell proliferation, matrix synthesis and gene expression. J Biomed Mater Res A. 2009; 88A: 23-33.

29. Yang K, Lee J, Cho SW. Engineering Biomaterials for Feeder-Free Maintenance of Human Pluripotent Stem Cells. Int J Stem Cells. 2012; 5: 1-5.

30. Miron RI, Gruber R, Hedbom E, Saulacic N, Zhang Y, Sculean A, et al. Impact of Bone Harvesting Techniques on Cell Viability and the Release of Growth Factors of Autografts. Clin Implant Dent Relat Res. 2013; 15: 481-9.

31. Manolagas SC, Cummings SR. Skeletal Aging: From Bench to Bed Side. J Gerontol A Biol Sci Med Sci. 2013; 68: 1195-6.

32. Reichert JC, Cipitria A, Epari DR, Saifzadeh S, Krishnakanth P, Berner A, et al. A Tissue Engineering Solution for Segmental Defect Regeneration in Load-Bearing Long Bones. Sci Transl Med. 2012; 4: 141ra93.

33. Pradel W, Mai R, Gedrange T, Lauer G. Cell passage and composition of culture medium effects proliferation and differentiation of human osteoblast-like cells from facial bone. J. Physiol. Pharmacol. 2008; 59 Suppl 5: 47-58.

34. Hayflick L. The limited in vitro lifetime of human diploid cell strains. Exp Cell Res. 1965; 37: 614-36

35. Frith JE, Thomson B, Genever PG. Dynamic three-dimensional culture methods enhance mesenchymal stem cell properties and increase therapeutic potential. Tissue Eng Part C Methods. 2010; 16: 735-49.

36. Karageorgiou V, Kaplan D. Porosity of 3D biomaterial scaffolds and osteogenesis. Biomaterials. 2005; 26: 5474-91.

37. Davey RB, Sparnon AL, Byard RW. Unusual donor site reactions to calcium alginate dressings. Burns. 2000; 26: 393-8.

38. Lee CSD, Moyer HR, Gittens I RA, Williams JK, Boskey AL, Boyan BD, et al. Regulating in vivo calcification of alginate microbeads. Biomaterials. 2010; 31: 4926-34.

39. Ma HL, Chen TH, Low-Tone Ho L, Hung SC. Neocartilage from human mesenchymal stem cells in alginate: Implied timing of transplantation. J Biomed Mater Res A. 2005; 74A: 439-46.

40. Glowacki J, Mizuno S, Greenberger JS. Perfusion Enhances Functions of Bone Marrow Stromal Cells in Three-Dimensional Culture. Cell Transplant. 1998; 7: 319-26.

41. Ratcliffe A, Niklason LE. Bioreactors and Bioprocessing for Tissue Engineering. Ann N Y Acad Sci. 2002; 961: 210-5.

42. Luckanagul J, Lee LA, Nguyen OL, Sitasuwan P, Yang X, Shazly T, et al Porous Alginate Hydrogel Functionalized with Virus as Three-Dimensional Scaffolds for Bone Differentiation. Biomacromolecules. 2012; 13: 3949-58.

43. Liechty KW, MacKenzie TC, Shaaban AF, Radu A, Moseley AB, Deans R, et al. Humanmesenchymal stem cells engraft and demonstrate site-specific differentiation after in utero transplantation in sheep. Nat Med. 2000; 6: 1282-6.
44. Khoo MLM, Shen $\mathrm{B}$, Tao $\mathrm{H}$, Ma DDF. Long-term serial passage and neuronal differentiation capability of human bone marrow mesenchymal stem cells. Stem Cells Dev. 2008; 17: 883-96.

45. Grellier M, Granja PL, Fricain JC, Bidarra SJ, Renard M, Bareille R, et al. The effect of the co-immobilization of human osteoprogenitors and endothelial cells within alginate microspheres on mineralization in a bone defect. Biomaterials. 2009; 30: 3271-8.

46. Li J, Song $\mathrm{Y}$, Zhang S, Zhao C, Zhang F, Zhang $\mathrm{X}$, et al. In vitro responses of human bone marrow stromal cells to a fluoridated hydroxyapatite coated biodegradable $\mathrm{Mg}-\mathrm{Zn}$ alloy. Biomaterials. 2010; 31: 5782-8.

47. Majore I, Moretti P, Stahl F, Hass R, Kasper C. Growth and Differentiation Properties of Mesenchymal Stromal Cell Populations Derived from Whole Human Umbilical Cord. Stem Cell Rev and Rep. 2011; 7: 17-31. 